\title{
Pancreatic alteration induced by incretins is consistent with the changes at the early stages of pancreatic carcinogenesis in the hamster model
}

\author{
Parviz M Pour $^{1,2 *}$ and Geoffrey Talmon ${ }^{2}$ \\ ${ }^{1}$ The Eppley/UNMC Cancer Center, University of Nebraska, USA \\ ${ }^{2}$ Department of Pathology and Microbiology, University of Nebraska, USA
}

\begin{abstract}
Background: GLP-1 analogs and DDP4 inhibitors, known as incretins, are used for the treatment of type 2 diabetes. Although several published clinical and experimental studies point to the beneficial effects of these drugs with negligible mild side effects, except for acute pancreatitis, detailed long-term effects of these drugs on the pancreas was missing. A recent report by the investigators at the UCLA, showing a profound expansion of pancreatic endocrine cells, hyperplasia of ductal epithelium and induction of endocrine lesions initiated a serious concern about the safety of these drugs.

Methods: Since these alterations were almost identical to those found at the early stages of pancreatic carcinogenesis in the hamster model, in the present study we compared the alterations published by the UCLA investigators with the alterations of the pancreas occurring during pancreatic carcinogenesis in the hamster model. Results and discussion: The results heightens the safety concern of these drugs and suggests that incretins should be considered as promoters of silent malignant pancreatic lesions and their use should be restricted to genuine long-standing diabetics and be restrained from individuals with new-onset diabetes (Type 3 diabetes) who may bear asymptomatic pancreatic cancer.
\end{abstract}

\section{Introduction}

Glucagon-like peptide 1 based therapies [GLP-1 receptor agonists (exenatide, liraglutide and lixisenatide) and DPP-4 inhibitors (sitagliptin, vildagliptin, saxagliptin and linagliptin)] have been available since 2005 for the treatment of Type 2 diabetes.

The efficacy of GLP-1 receptor agonists and DPP-4 inhibitors has been demonstrated. In terms of safety, the most common adverse events seen in clinical trials with GLP-1 receptor agonists are of gastrointestinal character, mainly nausea, vomiting and diarrhea. However, the incidence diminishes over time. Other identified risks include pancreatitis, immunogenicity, acute renal failure and rapid weight loss. Identified and potential risks with DPP-4 inhibitors include hypoglycemia, hypersensitivity, gastrointestinal disorders, pancreatitis, skin disorders, transaminase elevation and infections.

Although the manufacturers of the drugs have recently included acute pancreatitis as a serious side effect two fundamental concerns have been disregarded.

1. The long-term effects of the drugs on the structure of the pancreas and its consequences.

2. Physiological and pathological effects of the drug and their duration after their cessation.

The first concern was highlighted by a study of Butler et al. [1]. Using donor pancreases of Type 2 diabetics treated with incretins, they demonstrated massive and extended proliferation of pancreatic islet cells. Remarkably, the patterns of the morphological changes in their publication were almost identical to early lesions induced in the hamster pancreatic cancer model. The present report compares the pancreatic lesions published by Butler et al. [1] with those found during pancreatic carcinogenesis in the Syrian hamster model [2].

\section{Material and methods}

Histological and immunohistochemical material from published article [1]. Because of still ongoing Incretin Mimetics Pruducts Liability Litigation we were unable to obtain permission for the reproduction of the photomicrograph published by Butler et al. However, the readers can have access to the referenced figures by using the online version of that publication with the following URL: http://www.ncbi.nlm.nih. gov/pmc/articles/PMC3712065/

The presented figures from the hamster study (1974-2010) were obtained from the Tumor Archive at the UNMC Eppley Cancer Center.

\section{Results}

As described earlier in detail [2], in the hamster model, the earliest alteration in carcinogen-treated animals is the development of ductular structure within (intrainsular ducts) and around the islets (periinsular ducts). The initially tiny intrainsular ductules gradually enlarge. Due to

Correspondence to: Parviz Pour, Eppley Institute, Department of Pathology and Microbiology, University of Nebraska, USA, Tel: 402-559-4495, Fax: 402-5594651, E-mail: ppour@unmc.edu

Key words: GLP-1, pancreatic cancer, islet

Received: April 10, 2016; Accepted: May 13, 2016; Published: June 06, 2016 
serous and mucinous secretion by ductular cells, the ductules undergo cystic distention and the increasing pressure of liquid within the intrainsular ductules causes atrophy of the islet cells that appear as a small or tiny cell aggregate attached to the cystic wall (Figures 1 and 2). In animals exposed to a high dose of carcinogen the intra-and periinsular ductules undergo gradual hyperplasia, dysplasia and culminate in malignant glands that finally destroys the islets and invades the surrounding tissue [2, pp 85-86]. The figure $2 \mathrm{~A}$ in the publication [www. ncbi.nlm.nih.gov/pmc/articles/PMC3712065/] presents an identical pattern. In addition to the scattered islets of various sizes in that figure, there is one large islet in the lower middle field that contains a cystic duct and in the upper middle field another cystic duct with an atrophic islet inside. The remaining 3 cystic ducts in that figure appear to have lost the insular mass but still contain islet cells within their epithelium.

Another striking feature in induced lesions in the hamster model, as well as in human pancreatic cancer, is the presence of endocrine cells within the hyperplastic ducts, the number of which may seem to exceed the number of the ductal cells (Figure 3). Identical patterns has been observed in the study of Butler et al. (1) shown in their figure 2C, D, and E. Mucinous ductal cell hyperplasia bearing endocrine cells at the base of the epithelium, a characteristic finding in human pancreatic cancer and in the hamster model (has also been demonstrated in Fig 7A and 7C of that publication [www.ncbi.nlm.nih.gov/pmc/articles/ PMC3712065/].

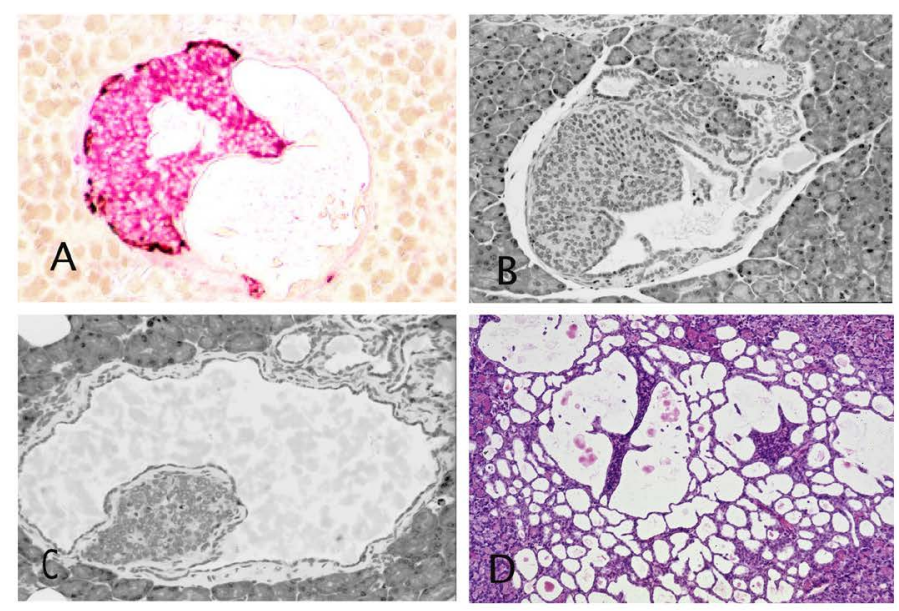

Figure 1.Intrainsularductular patterns. A and B: Islets of Syrian hamster treated once with pancreatic carcinogen, N-nitrosobis (2-oxopropyl) amine show cystic ducts occupying almost half the islet and are filled with floccus material. Insulin, red and glucagon, brown. ABC method $\mathrm{x}$ 40. C and D: Atrophic islets attached to the wall of the cystic ducts directly (C) or by a thin connective tissue (D) There are also numerous peri-insular ductular structures. H\&E x 40 (C), x20 (D). A,B and D are almost identical to the figure 2A published by Butler et al. [1].

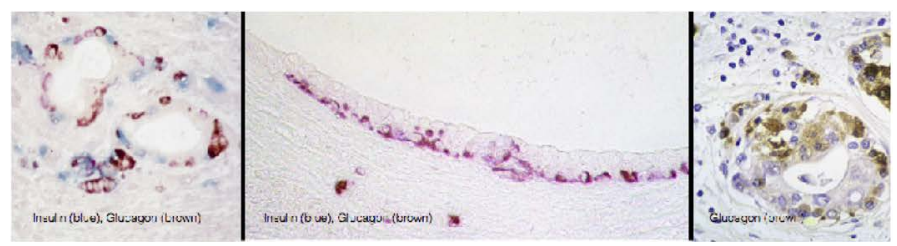

Figure 2. Large population of endocrine cells in malignant pancreatic adenocarcinoma in humans (A and C) and hamsters (B). These figures are strikingly similar to the figures C,D and $\mathrm{E}$, respectively, published by Butler et al. [1].

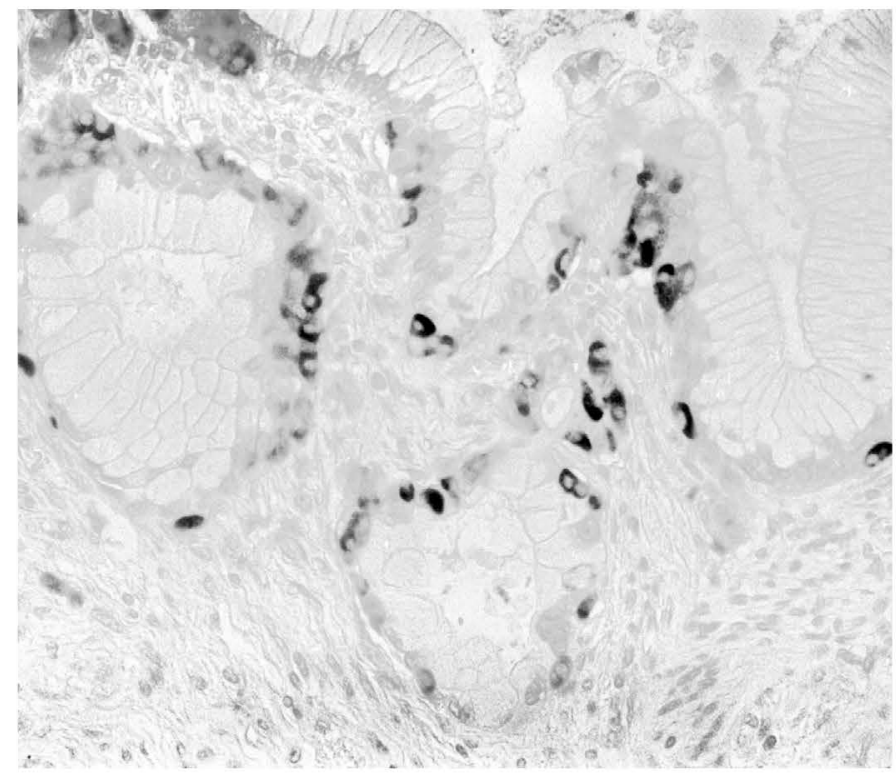

Figure 3. Human pancreatic mucinous adenocarcinoma with numerous endocrine cells in the basal epithelial layer. Identical lesions were illustrated as figure 7A and 7C by Butler et al.[1] in diabetic patients treated with incretin. A: Insulin (blue), glucagon (brown), somatostatin (black), ABC method, x40; B: insulin (red), glucagon (brown), ABC, x40; C: insulin (brown), $\mathrm{ABC}, \mathrm{x} 40$

\section{Discussion}

The present comparative study provides evidence that GLP1 treatment in type 2 diabetics causes profound alterations of the pancreas, consistent with early lesions occurring during pancreatic carcinogenesis in hamsters and in small pancreatic cancer in humans.

Some academic and industrial researchers [4,5] criticized the paper of Butler et al. [1]. Although some of their points from toxicological standards were reasonable, considering the parameters that they have recommended, thousands or even more brain-dead organ donors would be required to obtain statistically significant data. These authors did not propose how to obtain the adequate number of treated and untreated sex-, age- and BMI-matched donor pancreases receiving the same agent (of more than 20 that are currently in use) and disregarded the simple fact that the described unique alterations have never been reported in the pancreas of any normal or diabetic persons treated or untreated with various agents. And yet, the lesions were found only in the eight treated patients but in none of the 14 controls. The only comparative pancreatic abnormality associated with profound islet cell hyperplasia is the extremely rare adult type of hyperinsulinemic hypoglycemia [6,7], the morphological patters of which is entirely different.

The Committee for Medicinal Products for Human Use (CHMP) reviewed the publication by an ad-hoc expert meeting held on July 10 , 2013 and concluded that the results of the study by Butler et al. are not considered to constitute a new safety signal for the GLP 1 based therapies with respect to pancreatic safety. However, it was argued that due to the mechanism of action, there are still some uncertainties with respect to long-term pancreatic safety associated with these products and updates to the risk management plans (including planned and ongoing studies) and harmonization of warnings in the product information should be taken forward.

According to the Assessment report for GLP-1 based therapies on 
25 July 2013 EMA/474117/2013 in clinical trials, a few cases have been reported for some products (Table 1). Although the data currently available from clinical trials do not indicate an increased risk for pancreatic cancer with these medicines, in the post-marketing setting, cases of pancreatic cancer have been reported. A cumulative review of the cases has been undertaken and the majority (19 out of 29) had a time of onset of less than 6 months, a period considered too short to suggest a causal relationship.

The fate of the described lesions in the patients cannot be predicted. Will it remain stationary, regress or progress to frank malignancyr? In hamsters, the described alterations occur following low doses of pancreatic carcinogens and remain stationary although examination of the tissue by serial sectioning, in some instances, reveals progress to hyperplastic and neoplastic change, indicating that the lesions virtually present the early stages of cancer. It is possible that in these patients the advanced lesions have escaped their detection. Although the observed morphological alterations in the patients do not provide definite signs of malignancy and, regretfully, the genetic alteration of the lesions was not performed, presently the findings remain a controversial issue.

From the physiological pathological view, the massive insulin cell expansion but a lack of expected hyperinsulinemia, could be that the newly formed beta cells do not discharge their hormones (insulin, TGF-1) into the blood stream but rather like other hormones $[8,9]$ pour into the surrounding exocrine tissue by an autocrine or paracrine action. Support for this view is the increased pancreatic weight and ductal/ductular hyperplasia in incretin-treated animals and patients [1]. Although the amount of locally secreted insulin and IGF-1 may not be sufficient to stimulate malignant growth of the normal cells, it certainly can affect the latent premalignant and small cancers, which are reported to occur in up to $36 \%$ of individuals over 50-years old [10-21], and in a 9.5\% incidence of "silent" pancreatic cancer" in smokers [10]. The frequency of incidental premalignant and malignant pancreatic lesions $[10,15,17-21]$ indicate that the rate of pancreatic cancer is higher than generally believed. These silent cancers are vulnerable to rapid growth in any condition leading to increased insulin and IGF1 production. The reported and registered short latency of pancreatic cancer in clinical trials of incretins, as mentioned above, is in-line with this likelihood.

Hence, the presented data suggest that incretins could act as promoters of pancreatic cancer and their use should be restricted to genuine long-standing diabetics and be restrained from individuals with new-onset diabetes (Type 3 diabetes) who bear asymptomatic pancreatic cancer [22-27].

\section{References}

1. Butler AE, Campbell-Thompson M, Gurlo T, Dawson D, Atkinson M, et al. (2013)

Table 1. Few cases that have been reported for some products.

\begin{tabular}{|l|c|}
\hline Drug & Number of Cases \\
\hline Exenatide & 2 \\
\hline Liraglutide & 1 \\
\hline Lixisenatide & 3 \\
\hline Sitagliptin & 2 \\
\hline Saxagliptin & 8 \\
\hline Vildagliptin & 3 \\
\hline Linagliptin & A few? \\
\hline
\end{tabular}

In 9 out of 15 cases pancreatic cancer occurred within three months. In Saxagliptin group the time was 4-18 months. In others no definite time lapse was recorded
Marked Expansion of Exocrine and Endocrine Pancreas with Incretin Therapy in Humans with Increased Exocrine Pancreas Dysplasia and the Potential for GlucagonProducing Neuroendocrine Tumors. Diabetes 62: 2595-2604. [Crossref]

2. Pour PM (2012) Hamster as a pancreatic cancer model. www.panreapedia.org/ebook, pages $81-86$.

3. Kimura W, Morikane K, Esaki Y, Chan WC, Pour PM (1998) Histological and biological patterns of microscopic ductal adenocarcinomas detected incidentally at autopsy. Cancer 82: 1839-1849.

4. Bonner-Weir S, In't Veld PA, Weir GC (2014) Reanalysis of study of pancreatic effects of incretin therapy: methodological deficiencies. Diabetes Obes Metab 2014: 661-666. [Crossref]

5. Harja E, Lord J, Skyler JS (2013) An Analysis of Characteristics of Subjects Examined for Incretin Effects on Pancreatic Pathology. Diabetes Technol Ther 15: 609-618. [Crossref]

6. Qintar M, Sibai F, Taha M (2012) Hypoglycemia due to an adult-onset nesidioblastosis, a diagnostic and management dilemma. Avicenna J Med 2: 45-47. [Crossref]

7. Raffel A, Anlauf M, Hosch SB, Krausch M, Henopp T, et al. (2006) Hyperinsulinemic hypoglycemia due to adult nesidioblastosis in insulin-dependent diabetes. World $J$ Gastroenterol 12: 7221-7224. [Crossref]

8. von Wichert G, Jehle PM, Hoeflich A, Koschnick S, Dralle H, et al. (2000) Insulin-like growth factor-I is an autocrine regulator of chromogranin A secretion and growth in human neuroendocrine tumor cells. Cancer Res 60: 4573-4581. [Crossref]

9. Ohmura E, Okada M, Onoda N, Kamiya Y, Murakami H, et al. (1990) Insulin-like growth factor I and transforming growth factor alpha as autocrine growth factors in human pancreatic cancer cell growth. Cancer Res 50: 103-107. [Crossref]

10. Tomioka T, Andrén-Sandberg A, Fujii H, Egami H, Takiyama Y, et al. (1990) Comparative histopathological findings in the pancreas of cigarette smokers and nonsmokers. Cancer Lett 55: 121-128. [Crossref]

11. Kimura W, Morikane K, Esaki Y, Chan WC, Pour PM (1998) Histologic and biologic patterns of microscopic pancreatic ductal adenocarcinomas detected incidentally at autopsy. Cancer 82: 1839-1849. [Crossref]

12. Sommers SC, Murphy SA, Warren S (1954) Pancreatic duct hyperplasia and cancer. Gastroenterology 27: 629-640. [Crossref]

13. Collins JJ Jr, Craighead JE, Brooks JR (1966) Rationale for total pancreatectomy for carcinoma of the pancreatic head. N Engl J Med 274: 599-602. [Crossref]

14. Wilson C, Imrie CW (1986) Occult pancreatic cancer with recurrent acute pancreatitis Postgrad Med J 62: 765-767. [Crossref]

15. Tomita T, Vacha E Rengachery S, Watanabe I (1978) Occult adenocarcinoma of the pancreas in a patient with Lindau's disease. Am J Dig Dis 23: 80-83.

16. Compagno J, Oertel JE (1978) Microcystic adenomas of the pancreas (glycogen-rich cystadenomas): a clinicopathologic study of 34 cases. Am J Clin Pathol 69: 289-298. [Crossref]

17. Warshaw AL, Compton CC, Lewandrowski K, Cardenosa G, Mueller PR (1990) Cystic tumors of the pancreas. New clinical, radiologic, and pathologic observations in 67 patients. Ann Surg 212: 432-443. [Crossref]

18. Fernández-del Castillo C, Targarona, J, Thayer SP, Rattner DW, Brugge WR, et al (2003) Incidental pancreatic cysts: Clinicopathologic Characteristics and Comparison With Symptomatic Patients. Arch Surg 138: 427-434. [Crossref]

19. Ariyama J, Suyama M, Ogawa K, Ikari T, Nagaiwa J, et al. (1990) The detection and prognosis of small pancreatic carcinoma. Int J Pancreatol 7: 37-47. [Crossref]

20. Manabe T, Miyashita T, Ohshio G, Nonaka A, Suzuki T, et al. (1988) Small carcinoma of the pancreas. Clinical and pathologic evaluation of 17 patients. Cancer 62: 135-141. [Crossref]

21. Sataka K, Chung Y-S, Umeyama K, Takeuchi T, Kim YS (1991) The possibility of diagnosing small pancreatic cancer (less than $4.0 \mathrm{~cm}$ ) by measuring various tumor markers. Cancer 68: 149-152. [Crossref]

22. Permert J, Ihse I, Jorfeldt L, von Schenck H, Arnqvist HJ, et al. (1993) Pancreatic cancer is associated with impaired glucose metabolism. Eur J Surg 159: 101-107. [Crossref]

23. Schwarts SS, Zeidler A, Moossa AR, Kuku SF, Rubenstein AH (1978) A prospective study of glucose tolerance, insulin, C-peptide, and glucagon responses in patients with pancreatic carcinoma. Am J Dig Dis 23: 1107-1114. [Crossref] 
Pour PM (2016) Pancreatic alteration induced by incretins is consistent with the changes at the early stages of pancreatic carcinogenesis in the hamster model

24. Gullo L, Pezzilli R, Morselli-Labate AM; Italian Pancreatic Cancer Study Group (1994) Diabetes and the risk of pancreatic cancer. $N$ Engl J Med 331: 81-84. [Crossref]

25. Karmody AJ, Kyle J (1969) The association between carcinoma of the pancreas and diabetes mellitus. Br J Surg 56: 362-364. [Crossref]
26. Gullo L (1999) Diabetes and the risk of pancreatic cancer. Ann Oncol 4: 79-81.

27. Cetin M, Colak R, Bayram F, AltinbaÅŸ M, Unal A, et al. (2002) High prevalence of diabetes in patients with pancreatic cancer in central Anatolia, Turkey. Diabetes Res Clin Pract 58: 97-100. [Crossref]

Copyright: (C2016 Pour PM. This is an open-access article distributed under the terms of the Creative Commons Attribution License, which permits unrestricted use, distribution, and reproduction in any medium, provided the original author and source are credited. 